Article

\title{
The Effect of ECAP Temperature on the Microstructure and Properties of a Rolled Rare Earth Magnesium Alloy
}

\author{
Yun Tan ${ }^{1}$, Wei Li ${ }^{1, *}$, Weiwei Hu ${ }^{1}$, Xiaofang Shi ${ }^{1}$ and Liang Tian ${ }^{2}$ \\ 1 College of Material and Metallurgy, Guizhou University, Guiyang 550025, China; \\ tyl19941020@163.com (Y.T.); m18786670951@163.com (W.H.); 13017461042@163.com (X.S.) \\ 2 Guizhou Province Technology Innovation Service Center, Guiyang 550004, China; 18285117265@163.com \\ * Correspondence: liweiem@163.com; Tel.: +86-0851-83627068
}

Received: 3 April 2019; Accepted: 8 May 2019; Published: 12 May 2019

\begin{abstract}
Deformation of an as-rolled rare earth Mg-2Y-0.6Nd-0.6Zr alloy, at different temperatures, was carried out along the BC $\left(90^{\circ}\right.$ anticlockwise rotation of the samples after each ECAP pass) route by equal channel angular pressing (ECAP). The effects of the deformation temperature and the predeformation on the microstructure of the magnesium alloy were determined by the microstructure examination. The slip systems and texture change of the Mg-2Y-0.6Nd-0.6Zr alloy were investigated by X-ray diffraction (XRD) and electron backscattered diffraction (EBSD), after equal channel angular deformation. The results showed that after seven passes of rolling, the grain size in the Mg-2Y-0.6Nd-0.6Zr alloy was refined to approximately $22 \mu \mathrm{m}$ and the slip occurred mainly by a cylindrical slip and a pyramidal slip. After one pass of ECAP at $340^{\circ} \mathrm{C}$, the internal average grain size was significantly reduced to $11 \mu \mathrm{m}$, the cylindrical diffraction intensity clearly weakened, and the pyramidal diffraction intensity increased. EBSD pole figure analysis revealed that the base texture of the rolled Mg-2Y-0.6Nd-0.6Zr alloy weakened from 24.31 to 11.34 after ECAP. The mechanical properties indicated that the tensile strength and elongation of the rolled $\mathrm{Mg}-2 \mathrm{Y}-0.6 \mathrm{Nd}-0.6 \mathrm{Zr}$ alloy reached maximum values, when the deformation temperature was $340^{\circ} \mathrm{C}$.
\end{abstract}

Keywords: $\mathrm{Mg}-2 \mathrm{Y}-0.6 \mathrm{Nd}-0.6 \mathrm{Zr}$ alloy; equal channel angular pressing; predeformation; deformation temperature

\section{Introduction}

In recent years, to reduce energy consumption and environmental pollution caused by transportation, applications of new magnesium alloys, at high temperatures, have been studied by many researchers. Mg alloy is widely used in automobiles, aerospace, missiles, and other fields, because of its low density and high specific strength [1-4]. However, an inadequate number of slip planes at room temperature, results in poor workability, formability, and processing difficulty at room temperatures. Furthermore, the machining temperature of magnesium alloy is usually higher than $200{ }^{\circ} \mathrm{C}[5,6]$, which causes grain growth and a lower strength, due to the large grains. Therefore, it is important to improve the plasticity of magnesium alloys and their comprehensive properties [7-10].

Rare earth Mg alloys exhibit good strength and good creep resistance [11]. In particular, rare earth magnesium alloys show an improved high temperature performance, compared to conventional magnesium alloys, and are able to withstand service temperatures up to $\sim 250{ }^{\circ} \mathrm{C}$ [12]. Avvari et al. [13] showed that the grain refinement of an AZ61 magnesium alloy decreased with increasing deformation temperature, but the elongation increased. Liang et al. [14] simulated the extrusion process of an AZ31 magnesium alloy. The results demonstrated that the temperature plays an important role in the 
extrusion process-it not only affects the structure evolution but also determines the surface quality of the extruded sample. Garces et al. [15] found that a pre-extrusion treatment can effectively refine grains, thereby, improving the plasticity of the alloy. Reducing the deformation temperature of the subsequent equal channel angular pressing (ECAP), not only enables ECAP to be performed at a lower temperature but also improves the plasticity. Previous studies regarding the magnesium alloys were mostly done for as-cast magnesium alloys, the plasticity and strength of the wrought magnesium alloys have been less studied. In particular, for rare earth wrought magnesium alloys, studies of the grain size, texture change, and material properties, after ECAP, are still lacking.

Herein, hot rolling was used as the pretreatment for the Mg-2Y-0.6Nd-0.6Zr alloy, and the effect of the deformation temperature and predeformation on the microstructural evolution and mechanical properties of the Mg-2Y-0.6Nd-0.6Zr alloy were investigated.

\section{Materials and Methods}

In this study, the raw materials comprised pure magnesium and $\mathrm{Mg}-25 \% \mathrm{Y}, \mathrm{Mg}-25 \% \mathrm{Nd}$, and $\mathrm{Mg}-30 \% \mathrm{Zr}$ alloys. The pure magnesium components are listed in Table 1 . The mass ratio was determined according to Mg-2Y-0.6Nd-0.6Zr. RJ-5 was composed of $56 \%$ anhydrous carnallite, $30 \%$ $\mathrm{BaCl}_{2}$, and $14 \% \mathrm{CaF}_{2}$, which was used as a covering agent and a refining agent for melting. Before casting, the mold was preheated to $150 \pm 10^{\circ} \mathrm{C}$, and a cylindrical metal rod of $\Phi 30 \mathrm{~mm} \times 200 \mathrm{~mm}$ was cast and water-cooled, immediately after casting.

Table 1. Chemical composition of pure magnesium (mass fraction/\%).

\begin{tabular}{ccccccc}
\hline Al & Zn & Mn & Ni & Fe & Cu & Mg \\
\hline 0.0061 & 0.0035 & 0.014 & 0.0004 & 0.0017 & 0.0035 & Bal. \\
\hline
\end{tabular}

The cast billet was homogenized at $450{ }^{\circ} \mathrm{C}$ for $6 \mathrm{~h}$ and then air-cooled. Cylindrical bars were hot rolled, 7 times, using an F50-150 rounding machine. The total strain from rolling was 0.46 , and the alloy was preheated at $400{ }^{\circ} \mathrm{C}$, for $15 \mathrm{~min}$, before rolling. The bar was reheated to $400{ }^{\circ} \mathrm{C}$ and maintained at that temperature for 5-10 $\mathrm{min}$. The ECAP deformation of the as-rolled magnesium alloy was performed at $300^{\circ} \mathrm{C}, 320^{\circ} \mathrm{C}, 340^{\circ} \mathrm{C}$, and $360^{\circ} \mathrm{C}$, using the ECAP mold structure shown in Figure 1. As shown, the die used for ECAP had two characteristic corner angles of $\varphi=120^{\circ}$ and $\Psi=30^{\circ}$. The ECAP pressing was conducted via route $\mathrm{BC}\left(90^{\circ}\right.$ anticlockwise rotation of the samples after each ECAP pass) [16], and the specimens were lubricated with oil + graphite, inserted into the die, held until they reached the processing temperature, and then pressed at a constant rate of $0.4 \mathrm{~mm} / \mathrm{s}$.

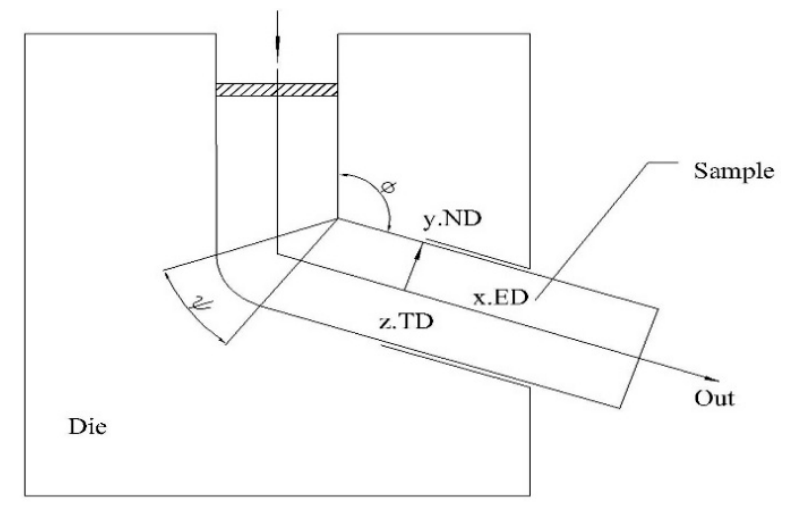

Figure 1. Equal channel angular pressing (ECAP) mold diagram.

The microstructure of the specimens was examined by optical microscopy (OM, Olympus, Japan). Samples for the OM investigation were ground and polished down with a $0.05 \mu \mathrm{m}$ alumina slurry. The microstructure analyses were conducted on the planes perpendicular to the transverse direction 
(TD), after the samples were chemically etched with a solution of picric acid, nitric acid, ethanol, and water.

Uniaxial tensile tests at room temperature were performed using an Instron 8501 testing machine (Instron, Canton, USA). The tensile specimen were fabricated, according to the standards GB/T 228-2002, as shown in Figure 2. The texture was analyzed by X-ray diffraction (PANalytical B.V., Aermoluo, Holland) with $\mathrm{CuK} \alpha$ radiation operated at $40 \mathrm{KV}$ and $40 \mathrm{~mA}$. The grain size was calculated from the micrographs, using Image-Pro Plus image analysis software. The tensile fracture of the sample was observed using a SUPRA 40 (ZEISS) scanning electron microscope (SEM, ZEISS, Oberkochen, Germany), with an acceleration voltage of $20 \mathrm{kV}$. Electron backscattered diffraction (EBSD) analysis was performed on a S-3400N scanning electron microscope (Hitachi, Tokyo, Japan), equipped with the TSL OIM Analysis 5 software package.

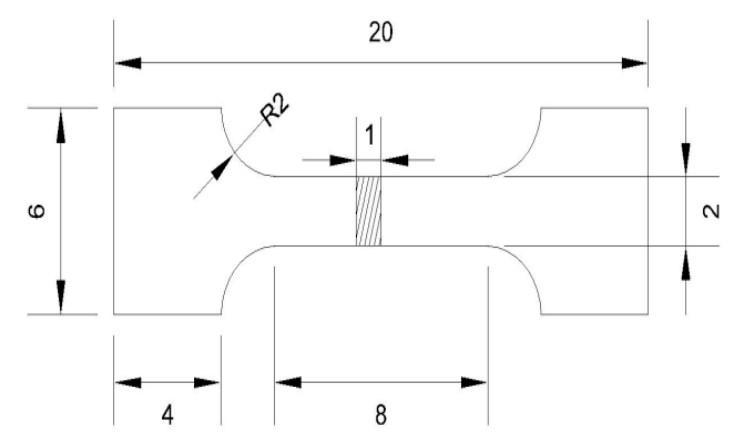

Figure 2. The dimension of the uniaxial tensile specimen (Unit: $\mathrm{mm}$ ).

\section{Results and Discussion}

\subsection{Effect of Predeformation Temperature on the Microstructure and Properties of the Alloy}

In the experiment, different rolling temperatures of $360^{\circ} \mathrm{C}, 380{ }^{\circ} \mathrm{C}$, and $400{ }^{\circ} \mathrm{C}$ were selected. A photograph of the samples after rolling is shown in Figure 3. Clearly, when the rolling temperature was $360^{\circ} \mathrm{C}$, cracks appeared on the surface of the sample, and the surface quality was poor. With an increasing rolling temperature, the surfaces of the samples were smoother, and the quality was better. Typically, it was difficult to initiate the slip systems in magnesium alloys at low temperatures, and the stress concentration caused shear fracture; if the temperature was too high, the grain size increased, and the plasticity affected the performance of the alloy.

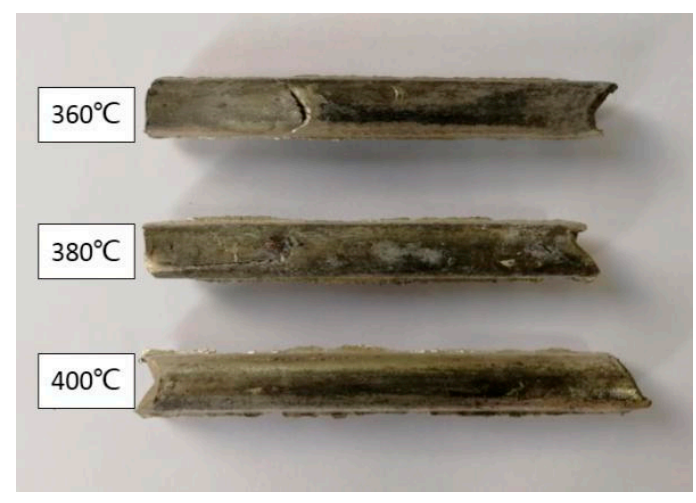

Figure 3. Photograph of rolled samples.

Figure 4a presents the microstructure of the magnesium alloy in a uniform as-cast state. It appears that the sample was homogeneous and comprised large grains with a size of $85 \mu \mathrm{m}$. Moreover, the grain structure and grain boundaries were relatively clean and uniform. After seven rolling passes at $400{ }^{\circ} \mathrm{C}$, the microstructure was finer than that in the as-cast state. As shown in Figure $4 \mathrm{~b}$, an average 
grain size of $22 \mu \mathrm{m}$ was attained after rolling. Consequently, as the rolling temperature increased to $400{ }^{\circ} \mathrm{C}$, the required activation energy for the dislocation slip was provided, and the critical resolved shear stress (CRSS) of the non-basal slip systems was reduced [17-19]. In addition, the non-basal slip systems were initiated, such that, the grains were mutually coordinated and deformed, during the rolling process, the macroscopic defects basically disappeared, and the appearance of the rolled samples was good.
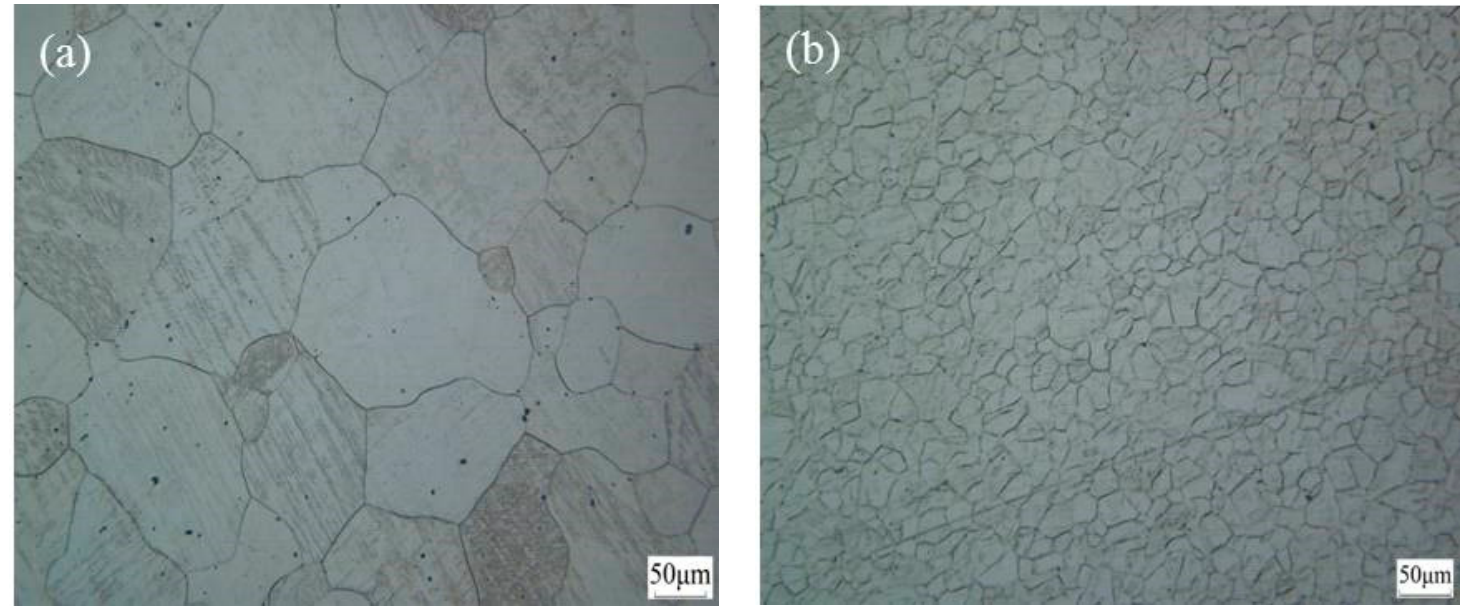

Figure 4. Optical microstructures of the Mg-2Y-0.6Nd-0.6Zr magnesium alloy: (a) As-cast state, and (b) as-rolled state.

Adding a small amount of rare earth elements to the magnesium alloys caused the stacking fault energy to improve and the alloy to become prone to cross-slip. During the deformation process, dislocation multiplication, and dislocation tangles occurred, and the density of dislocations and deformation energy storage increased, simultaneously. Non-basal slip, cross-slip, and dislocation climb occurred during deformation, which was favorable for a dynamic recrystallization; recrystallized grains grew around large grains, and most large grains were gradually replaced by the recrystallized fine grains. For the Mg-2Y-0.6Nd-0.6Zr alloy studied here, some of the second phase particles precipitated after high-temperature rolling, and the second phase particles were mostly distributed at the grain boundaries. It could be observed from Figure $4 \mathrm{~b}$ that the grain refinement was substantial.

Figure 5 shows the true stress-strain curves of the samples, and the corresponding values of the ultimate tensile strength (UTS), $0.2 \%$ proof stress (YS), and tensile elongation to failure (TEF) are listed in Table 2. Compared with the as-cast sample, the seven-pass rolling procedure resulted in substantial increases in the UTS and YS, and a decrease in TEF, all of which were attributed to work hardening during rolling. The tensile strength improved by $61 \%$ from $150 \mathrm{MPa}$ to $246 \mathrm{MPa}$, but the plasticity was significantly reduced, and the elongation was reduced by approximately $78 \%$. Therefore, the as-rolled magnesium alloy exhibited a greater brittleness and higher strength than that of the as-cast alloy, but its plasticity was poor. This result occurred because the Mg-2Y-0.6Nd- $0.6 \mathrm{Zr}$ alloy could not be recrystallized and softened, when rolling at $400{ }^{\circ} \mathrm{C}$. As the deformation degree increased, the work hardening effect gradually increased, and grain refinement occurred. There were a large number of dislocations generated, so, when the rolling occurred, the YS of the alloy substantially improved and the TEF decreased. 


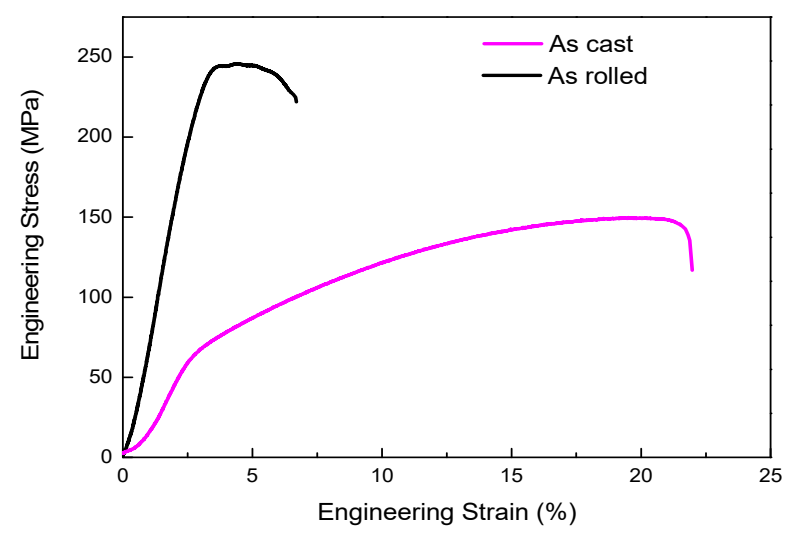

Figure 5. Mg-2Y-0.6Nd-0.6Zr alloy stress and strain curves of the as-cast and as-rolled states.

Table 2. The mechanical properties of the Mg-2Y-0.6Nd-0.6Zr alloy.

\begin{tabular}{cccc}
\hline Sample & UTS (MPa) & YS (MPa) & TEF\% \\
\hline As-cast & 150 & 64 & 17.00 \\
As-rolled & 246 & 216 & 3.75 \\
\hline
\end{tabular}

\subsection{Microstructure Evolution of $\mathrm{Mg}$ Alloy at Different Deformation Temperatures}

The microstructures of the samples after ECAP at different temperatures are shown in Figure 6. When the sample was extruded at a high temperature, a slight deformation occurred before entering the shearing zone, and then, severe plastic deformation occurred, after entering the shearing zone. The high temperature simultaneously provided nuclear driving forces for the equal-channel angular pressed wrought magnesium alloy. However, due to the increase in the dislocation density and increase in internal storage energy, dynamic recrystallization occurred in the shear band, and the crystal grains were refined [20-22]. When the deformation temperature of the ECAP process was $300^{\circ} \mathrm{C}$, a large number of twins appeared inside the coarse grains, and the structure was relatively uniform, as shown in Figure 6a. However, there were fine cracks in the core along the grain boundary. The potential slip systems of an as-rolled magnesium alloy were not usually activated at $300{ }^{\circ} \mathrm{C}$, which made it difficult to initiate the deformation of the c-axis. When shear deformation along the (110) planes occurred as a result of the ECAP, it was difficult for each slip system to activate. Hence, there was a phenomenon of cracking along the crystal, which seriously affected its mechanical properties.

When ECAP at $320^{\circ} \mathrm{C}$ was performed for 1 pass, as shown in Figure $6 \mathrm{~b}$, the recrystallized area increased, and the proportion of small grains increased, compared with that at $300^{\circ} \mathrm{C}$. However, the grain structure was inhomogeneous and consisted of elongated grains with relatively fine grains. At $340{ }^{\circ} \mathrm{C}$, no twin structure was found, the alloy structure was further refined, the average grain size was approximately $11 \mu \mathrm{m}$, and the refining effect was better than that of the extrusion at $320^{\circ} \mathrm{C}$, for 1 pass, as shown in Figure 6c. As the temperature increased (as shown in Figure 6d), it was clear that the recrystallized grains began to grow and form a fully recrystallized microstructure. 

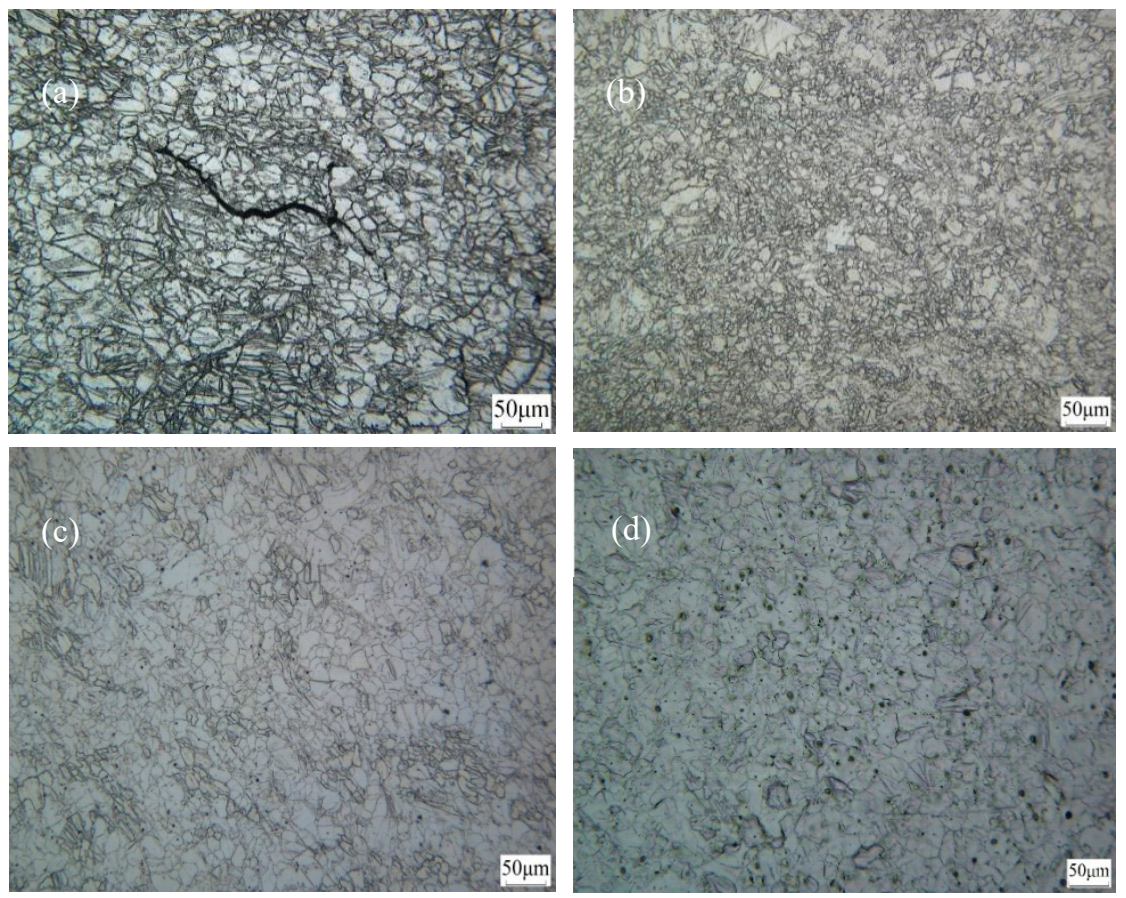

Figure 6. Optical microstructures of the deformed $\mathrm{Mg}-2 \mathrm{Y}-0.6 \mathrm{Nd}-0.6 \mathrm{Zr}$ alloy after ECAP at different temperatures: (a) $300{ }^{\circ} \mathrm{C}$, (b) $320^{\circ} \mathrm{C}$, (c) $340{ }^{\circ} \mathrm{C}$, and (d) $360{ }^{\circ} \mathrm{C}$.

\subsection{Texture Evolution of the $\mathrm{Mg}$ Alloy at Different Temperatures}

Figure 7 presents the XRD pattern of the original sample and the extruded state after ECAP at different deformation temperatures. It could be observed from the figure that the strongest diffraction peak of the as-rolled sample was the $\{10 \overline{1} 0\}$ peak, followed by the $\{10 \overline{1} 1\}$ peak, which meant that the slip surface in the as-rolled sample had a clear preferred orientation, and a portion of the pyramidal slip system was activated at some point. However, after ECAP, the $\{10 \overline{1} 1\}$ diffraction peak was significantly enhanced, and the $\{10 \overline{1} 0\}$ diffraction peak was significantly weakened. In addition, the intensities of diffraction peaks, such as $\{10 \overline{1} 2\},\{11 \overline{2} 0\}$, and $\{10 \overline{1} 3\}$, were enhanced after ECAP, which was due to more pyramidal slip systems being activated with the temperature increase. The main slipping mechanisms of the as-rolled sample were cylindrical pyramidal slips [23,24]. After ECAP, the intensity of the pyramidal slip system was clearly enhanced. This result occurred because the sample experienced a significant orientation change, after the ECAP deformation, which led to a decrease in the cylindrical orientation and an increase in the pyramidal orientation. Thus, the slip line helped the slip system to start, and the plasticity was also improved. At different ECAP deformation temperatures, the peak height of the $\mathrm{Mg}$ matrix phase in the sample, experienced almost no change, indicating that the original Mg-2Y-0.6Nd-0.6Zr alloy was slowly transformed from the typical rolled state texture to the equal-channel angular pressed texture, and the orientation did not change. The relationship between the strength of the material and the grain size, at this time, was in accordance with the Hall-Petch formula.

The pole figure of the as-rolled sample and the sample after ECAP at $340^{\circ} \mathrm{C}$, is shown in Figure 8 . The as-rolled sample exhibited a strong basal texture of 24.31 and a texture along $15^{\circ}$, to the normal direction (ND), indicating that the direction of rolling and the basal (0001), occurred for a deflection of $15^{\circ}$. After a one-time extrusion at $340{ }^{\circ} \mathrm{C}$, the basal texture intensity of the sample weakened from 24.31 to 11.34. As a result, due to the shear deformation introduced during the extrusion process, the orientation of the applied stress was changed, which could effectively change the texture of the magnesium alloy and promote texture weakening. This observation indicated that the basal texture could be appropriately reduced by ECAP. 


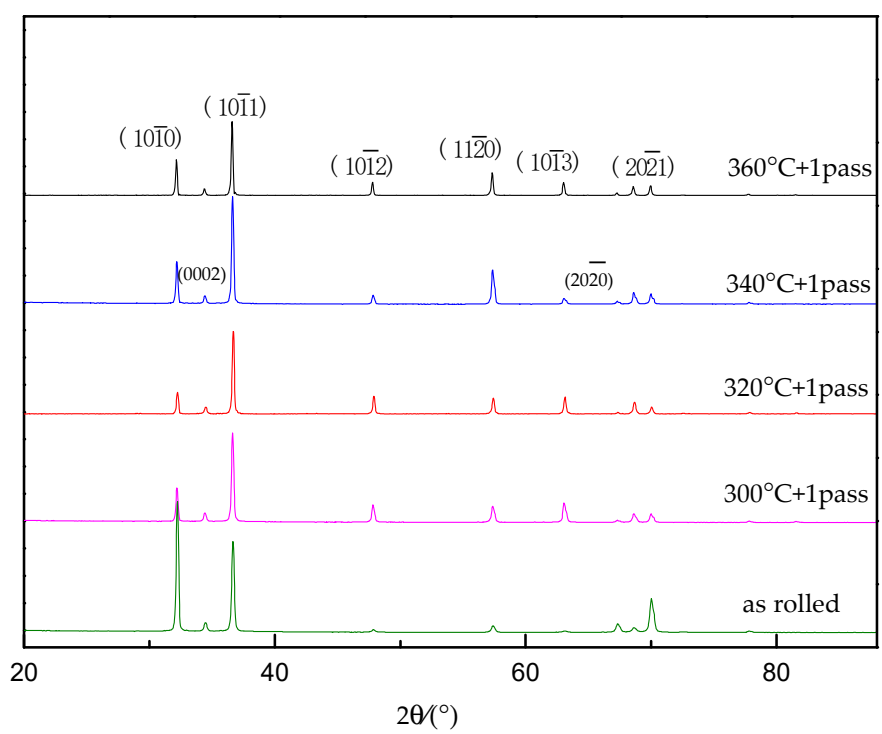

Figure 7. XRD spectra of Mg-2Y-0.6Nd-0.6Zr alloy during ECAP deformation at different temperatures.
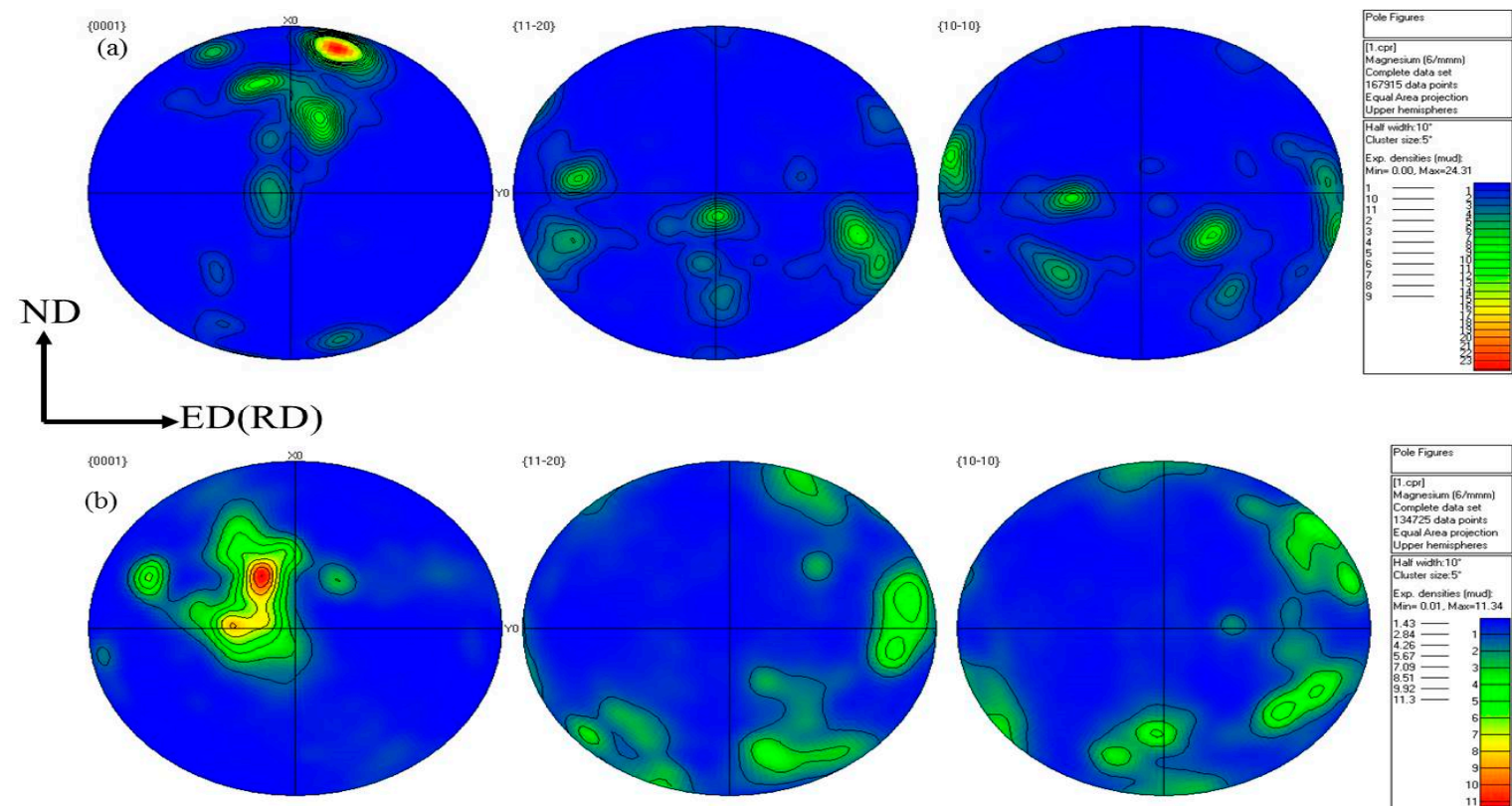

Figure 8. Electron backscattered diffraction (EBSD) analysis results: pole figures of the as-rolled state (a) and extruded state (b).

Consequently, to assess the effect of texture on strength, the Schmid factors were determined in terms of basal slip. Figure 9 shows the Schmid factor maps of the Mg-2Y-0.6Nd-0.6Zr alloy samples. The Schmid factor of the as-rolled sample was lower than that of the sample after ECAP, and the average Schmid factors were 0.28 and 0.32 , respectively. Therefore, when the Schmid factor value was relatively high, more slip systems could be initiated in the alloy. The stress generated by the dislocation slip and the entanglement was dispersed, which decreased the tensile strength, as demonstrated for the sample after ECAP [25]. 

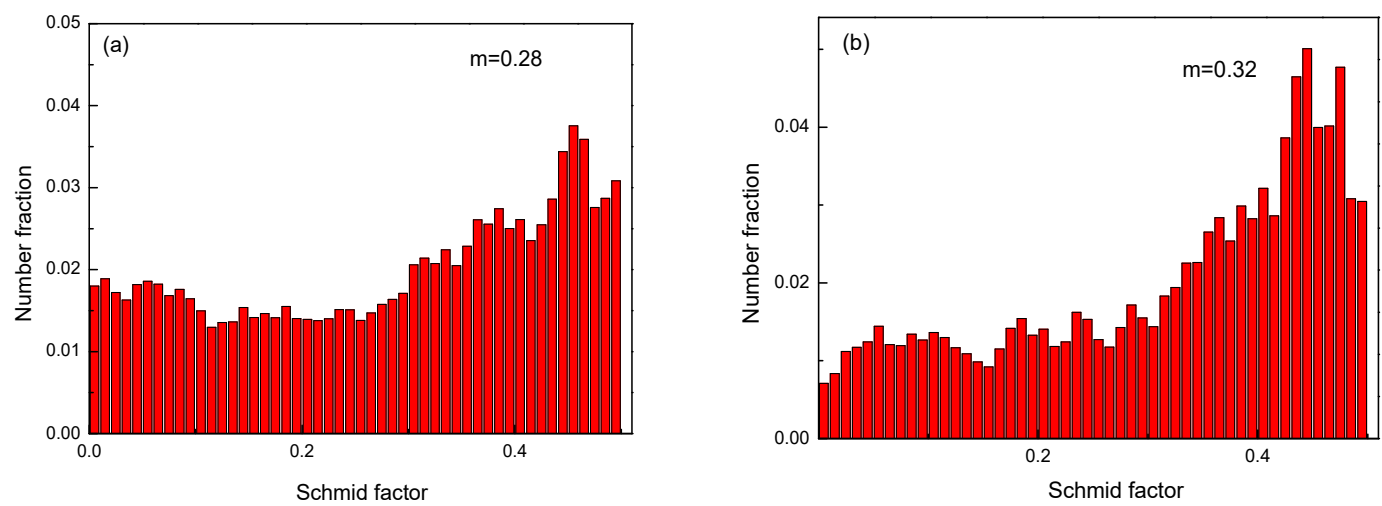

Figure 9. Schmid factor maps of the Mg-2Y-0.6Nd-0.6Zr alloy samples. (a) As rolled and (b) at $340{ }^{\circ} \mathrm{C}$.

\subsection{Mechanical Properties}

It can be observed from Figure 10a that the UTS was improved, after one-pass extrusion at different temperatures, by ECAP. The corresponding values of the ultimate tensile strength (UTS) and tensile elongation to failure (TEF) are listed in Table 3. In particular, the UTS after ECAP was higher than that of the as-cast sample, but the TEF clearly decreased at $300{ }^{\circ} \mathrm{C}$. This phenomenon might be due to the core cracks. Although the grain refinement was obvious, core cracking occurred, which substantially affected the tensile strength. When extruded at $340^{\circ} \mathrm{C}$ for 1 pass, the mechanical properties improved, compared with that of the other pressing temperatures. The UTS and TEF at $340{ }^{\circ} \mathrm{C}$ reached the maximum values, and the UTS increased by $50 \%$, compared with that of the as-cast samples. However, the UTS of the as-ECAPed samples decreased, relative to the as-rolled sample. According to the Hall-Petch relationship, the strength of the material should increase with a decreasing grain size, but its mechanical properties exhibited an anti-Hall-Petch relationship, after the ECAP deformation. Kim et al. [26] attributed this phenomenon to a texture softening effect greater than that of grain refinement, resulting in a decrease in the strength of the magnesium alloy. Jing et al. [27] also observed this phenomenon when studying the ECAP of the Mg-10.73Li-4.49Al-0.52Y alloy. Research has shown that the deformation of magnesium alloys by ECAP is affected by an increase of the grain boundaries, a new texture, and by grain refinement. Moreover, the effect of grain boundaries and texture softening was greater than that of grain refinement [28]. At the same time, it was also considered that during the ECAP process, the partial work hardening caused by rolling was eliminated.

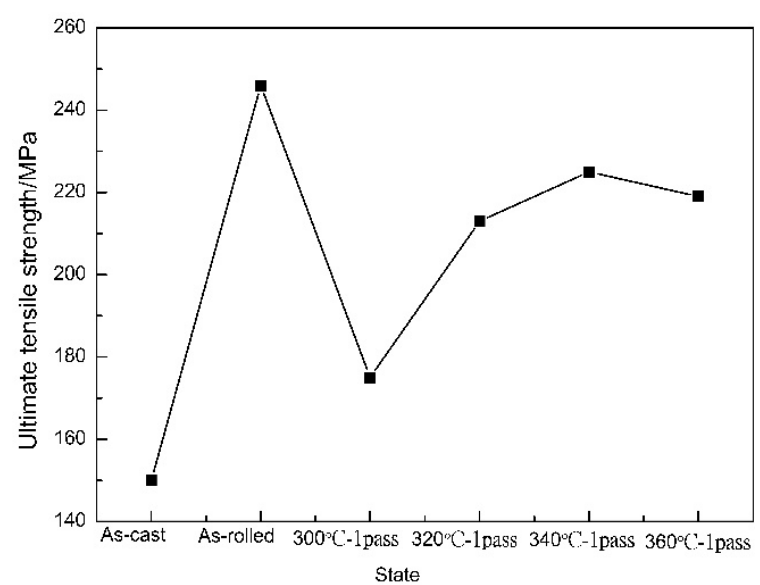

(a)

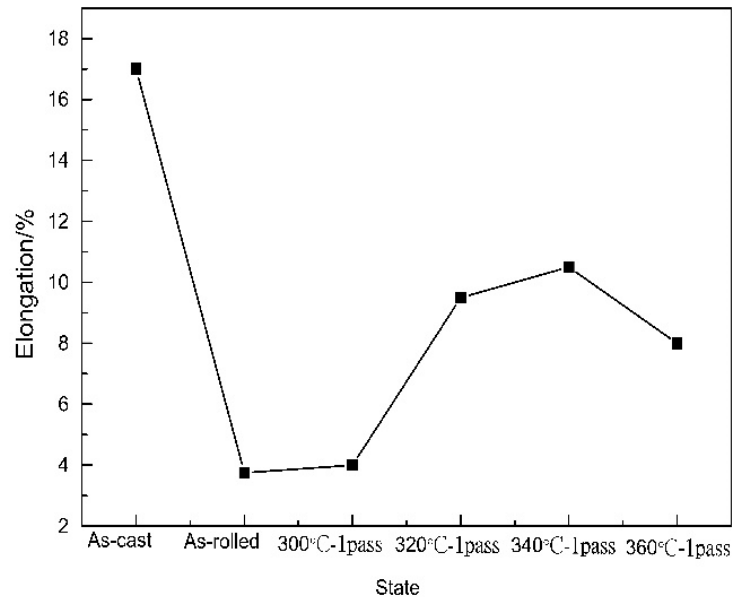

(b)

Figure 10. Tensile strength and elongation of the $\mathrm{Mg}-2 \mathrm{Y}-0.6 \mathrm{Nd}-0.6 \mathrm{Zr}$ alloy extruded by the ECAP, in a uniform state, at different temperatures: (a) Ultimate tensile strength, and (b) elongation. 
Table 3. The mechanical properties of the samples.

\begin{tabular}{ccc}
\hline State & UTS (MPa) & TEF\% \\
\hline As-cast & 150.00 & 17.00 \\
As-rolled & 246.00 & 3.75 \\
$300^{\circ} \mathrm{C}-1$ pass & 175.00 & 4.00 \\
$320^{\circ} \mathrm{C}-1$ pass & 213.00 & 9.50 \\
$340^{\circ} \mathrm{C}-1$ pass & 225.00 & 10.50 \\
$360^{\circ} \mathrm{C}-1$ pass & 219.00 & 8.00 \\
\hline
\end{tabular}

Figure 11 shows the fracture morphology of the Mg-2Y-0.6 Nd-0.6Zr magnesium alloy. It can be observed from Figure 11a that the as-rolled sample experienced brittle fracture and had shallow dimples, indicating a typical grain boundary fracture. After 1 pass of extrusion via ECAP, the area of a single grain boundary was reduced, and finer grains were formed. Moreover, the fracture mode changed from a brittle fracture to a ductile fracture, and a large number of dimples appeared on the tensile fracture surface. As shown in Figure 11d, the fracture surface exhibited a fluvial pattern, with a large dimple and a tearing ridge on the crystal surface, which indicated an intergranular toughness fracture.

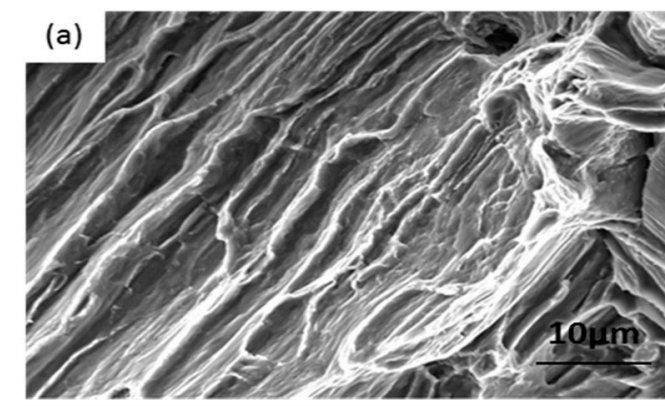

(c)
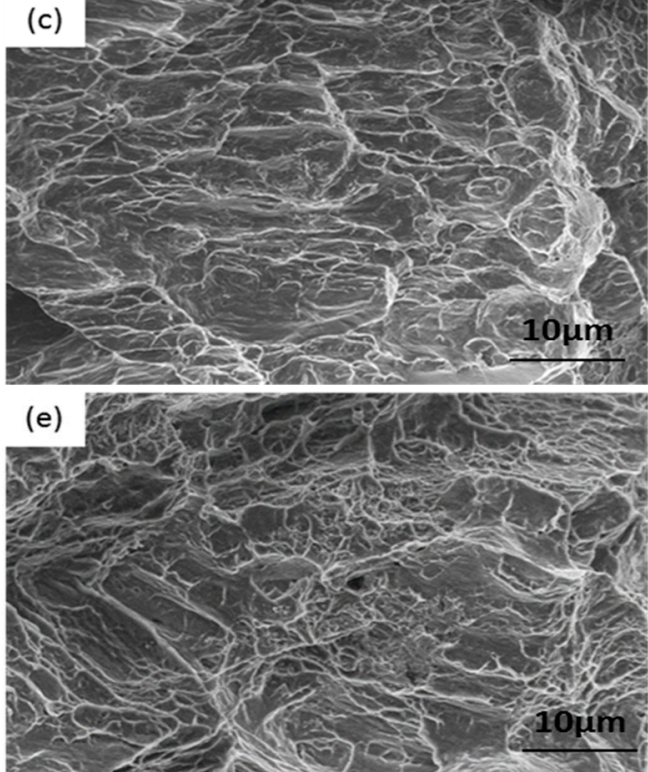

(e) (b)

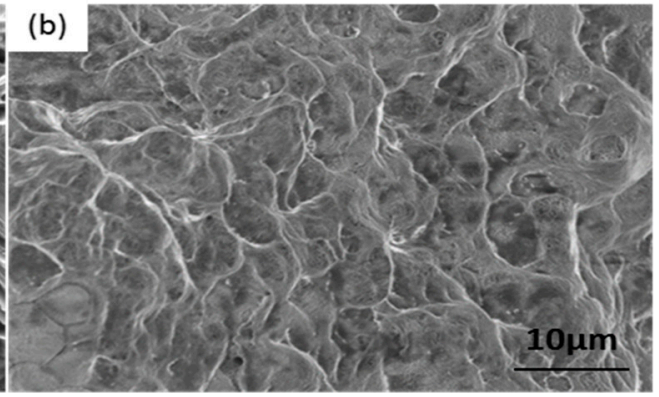

(d)

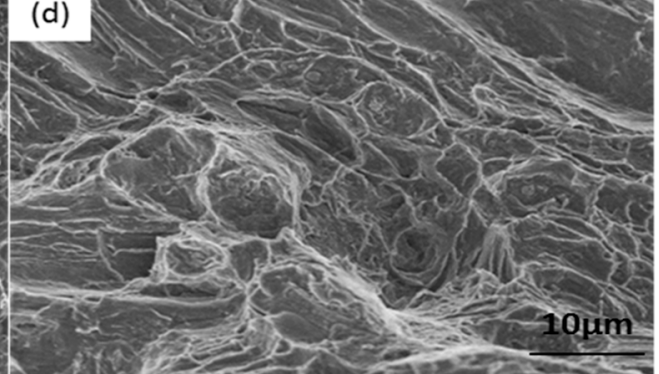

(f)

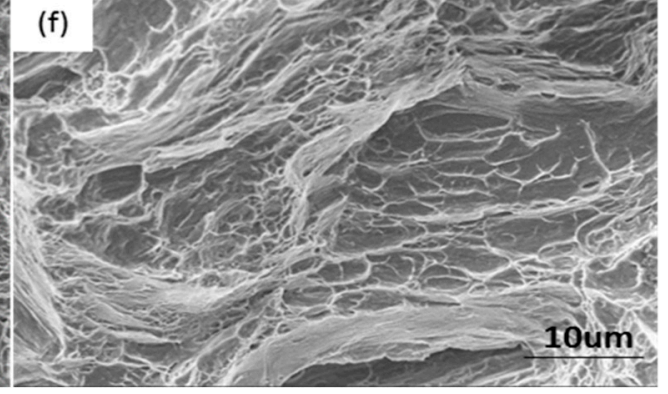

Figure 11. Tensile fracture SEM morphology of the ECAP extruded-rolled Mg-2Y-0.6Nd-0.6Zr alloy: (a) As cast, (b) as rolled, (c) $300{ }^{\circ} \mathrm{C}$, (d) $320^{\circ} \mathrm{C}$, (e) $340{ }^{\circ} \mathrm{C}$, and (f) $360^{\circ} \mathrm{C}$.

\section{Conclusions}

1. Of the ECAP temperatures considered, the best rolling temperature of the $\mathrm{Mg}-2 \mathrm{Y}-0.6 \mathrm{Nd}-0.6 \mathrm{Zr}$ alloy was $400^{\circ} \mathrm{C}$. Compared with the as-cast sample, the average grain size of the rolled samples was refined from $85 \mu \mathrm{m}$ to $22 \mu \mathrm{m}$, and the UTS improved from $150 \mathrm{MPa}$ to $246 \mathrm{MPa}$, increasing by 
approximately $61 \%$, compared with the as-cast magnesium alloy. However, the TEF was greatly reduced because of work hardening.

2. Compared with the as-cast sample, the sample after ECAP exhibited grain refinement with a minimum grain size of $11 \mu \mathrm{m}$, but the elongation increased, and the tensile strength substantially decreased. The decrease in tensile strength was due to the texture weakening and eliminating the effect of partial work hardening, after ECAP.

3. The sample processed with ECAP at $340{ }^{\circ} \mathrm{C}$, achieved the best comprehensive properties, with a UTS of $225 \mathrm{MPa}$ and a TEF of $10.5 \%$. As a result, when the rare earth Mg-2Y-0.6Nd-0.6Zr alloy was subjected to ECAP, a suitable deformation temperature was $340^{\circ} \mathrm{C}$.

Author Contributions: W.H., X.S., conceived and designed the experiment; L.T. and X.S. contributed to retrieve documents; Y.T. collected the data; W.H. made the graph; Y.T. analyzed the data and wrote the paper. This article was checked and revised by W.L.

Acknowledgments: This research was supported by the National Natural Science Foundation of China (51661007), China Postdoctoral Science Foundation (2018M633416), and the Guizhou Science and Technology Fund (qian ke heJ [2017] 1022).

Conflicts of Interest: The authors declare no conflict of interest.

\section{References}

1. Luo, A.A.; Mishra, R.K.; Powell, B.R.; Sachdev, A.K. Magnesium Alloy Development for Automotive Applications. Mater. Sci. Forum. 2012, 706, 69-82.

2. Dong, J.; Dong, Q.; Dai, Y.; Xing, H.; Han, Y.; Ma, J.; Zhang, J.; Wang, J.; Sun, B. Study on structure homogeneity of plate sample with large dimension during equal channel angular pressing (ECAP). J. Mater. Res. 2016, 31, 3420-3427. [CrossRef]

3. $\mathrm{Su}, \mathrm{C}$; $\mathrm{Lu}, \mathrm{L} . ; \mathrm{Lai}, \mathrm{M}$. A model for the grain refinement mechanism in equal channel angular pressing of $\mathrm{Mg}$ alloy from microstructural studies. Mater. Sci. Eng. A 2006, 434, 227-236. [CrossRef]

4. Gunderovae, D.V.; Polyakova, A.V.; Semenovaa, I.P.; Raab, G.I.; Churakovaa, A.A.; Gimaltdinova, E.I.; Sabirov, I.; Segurado, J.; Sitdikov, V.D.; Alexandrov, I.V.; et al. Evolution of microstructure, macrotexture and mechanical properties of commercially pure Ti during ECAP-conform processing and drawing. Mater. Sci. Eng. A 2013, 562, 128-136. [CrossRef]

5. Kaseem, M.; Chung, B.K.; Yang, H.W.; Hamad, K.; Ko, Y.G. Effect of Deformation Temperature on Microstructure and Mechanical Properties of AZ31 Mg Alloy Processed by Differential-Speed Rolling. J. Mater. Sci. Technol. 2015, 31, 498-503. [CrossRef]

6. Murai, T.; Matsuoka, S.-I.; Miyamoto, S.; Oki, Y. Effects of extrusion conditions on microstructure and mechanical properties of AZ31B magnesium alloy extrusions. J. Mater. Process. Technol. 2003, 141, 207-212. [CrossRef]

7. Liu, X.; Chen, R.; Han, E. High temperature deformations of Mg-Y-Nd alloys fabricated by different routes. Mater. Sci. Eng. A 2008, 497, 326-332.

8. Zhao, Y.; Liao, X.; Jin, Z.; Valiev, R.; Zhu, Y.; Liao, X. Microstructures and mechanical properties of ultrafine grained $7075 \mathrm{Al}$ alloy processed by ECAP and their evolutions during annealing. Acta Mater. 2004, 52, 4589-4599. [CrossRef]

9. Chen, J.; Lu, L.; Lu, K. Hardness and strain rate sensitivity of nanocrystalline Cu. Scr. Mater. 2006, 54, 1913-1918. [CrossRef]

10. Kim, H.-K. The grain size dependence of flow stress in an ECAPed AZ31 Mg alloy with a constant texture. Mater. Sci. Eng. A 2009, 515, 66-70. [CrossRef]

11. Mordike, B.L. Creep-resistant magnesium alloys. Mater. Sci. Eng. A 2002, 324, 103-112. [CrossRef]

12. Antion, C.; Donnadieu, P.; Perrard, F.; Deschamps, A.; Tassin, C.; Pisch, A. Hardening precipitation in a Mg-4Y-3RE alloy. Acta Mater. 2003, 51, 5335-5348. [CrossRef]

13. Avvari, M.; Narendranath, S. Influence of Route-R on wrought magnesium AZ61 alloy mechanical properties through equal channel angular pressing. J. Magnes. Alloy. 2014, 2, 159-164. [CrossRef]

14. Liang, S.; Liu, Z.; Wang, E. Simulation of extrusion process of AZ31 magnesium alloy. Mater. Sci. Eng. A 2009, 499, 221-224. [CrossRef] 
15. Garces, G.; Muñoz-Morris, M.A.; Morris, D.G.; Perez, P.; Adeva, P. Optimization of strength by microstructural refinement of MgY2Zn1 alloy during extrusion and ECAP processing. Mater. Sci. Eng. A 2014, 614, 96-105. [CrossRef]

16. Nakashima, K.; Horita, Z.; Nemoto, M.; Langdon, T.G. Development of a multi-pass facility for equal-channel angular pressing to high total strains. Mater. Sci. Eng. A 2000, 281, 82-87. [CrossRef]

17. Chapuis, A.; Driver, J.H. Temperature dependency of slip and twinning in plane strain compressed magnesium single crystals. Acta Mater. 2011, 59, 1986-1994. [CrossRef]

18. Krajňák, T.; Minárik, P.; Stráská, J.; Gubicza, J.; Máthis, K.; Janeček, M. Influence of equal channel angular pressing temperature on texture, microstructure and mechanical properties of extruded AX41 magnesium. J. Alloy. Compd. 2017, 705, 273-282. [CrossRef]

19. Máthis, K.; Köver, M.; Stráská, J.; Trojanová, Z.; Džugan, J.; Halmešová, K. Micro-Tensile Behavior of Mg-Al-Zn Alloy Processed by Equal Channel Angular Pressing (ECAP). Materials 2018, 11, 1644. [CrossRef] [PubMed]

20. Li, N.; Huang, G.; Zhong, X.; Liu, Q. Deformation mechanisms and dynamic recrystallization of AZ31 Mg alloy with different initial textures during hot tension. Mater. Des. 2013, 50, 382-391. [CrossRef]

21. Hradilova, M.; Montheillet, F.; Fraczkiewicz, A.; Desrayaud, C.; Lejček, P. Effect of Ca-addition on dynamic recrystallization of $\mathrm{Mg}-\mathrm{Zn}$ alloy during hot deformation. Mater. Sci. Eng. A 2013, 580, 217-226. [CrossRef]

22. Jiang, Y.; Tang, G.; Shek, C.H.; Xie, J.; Xu, Z.; Zhang, Z. Mechanism of electropulsing induced recrystallization in a cold-rolled Mg-9Al-1Zn alloy. J. Alloy. Compd. 2012, 536, 94-105. [CrossRef]

23. Wei, Y.; Wang, Q.; Zhu, Y.; Zhou, H.; Ding, W.; Chino, Y.; Mabuchi, M.; Ding, W. Superplasticity and grain boundary sliding in rolled AZ91 magnesium alloy at high strain rates. Mater. Sci. Eng. A 2003, 360, 107-115. [CrossRef]

24. Cheng, W.; Tian, L.; Ma, S.; Bai, Y.; Wang, H. Influence of Equal Channel Angular Pressing Passes on the Microstructures and Tensile Properties of Mg-8Sn-6Zn-2Al Alloy. Materials 2017, 10, 708. [CrossRef] [PubMed]

25. Minárik, P.; Veselý, J.; Král, R.; Bohlen, J.; Kubásek, J.; Janeček, M.; Stráská, J. Exceptional mechanical properties of ultra-fine grain Mg-4Y-3RE alloy processed by ECAP. Mater. Sci. Eng. A 2017, 708, 193-198. [CrossRef]

26. Kim, W.; Hong, S.; Kim, Y.; Min, S.; Jeong, H.; Lee, J. Texture development and its effect on mechanical properties of an AZ61 Mg alloy fabricated by equal channel angular pressing. Acta Mater. 2003, 51, 3293-3307. [CrossRef]

27. Kong, J.; Liu, Q.; Kang, Z.X. Microstructure and mechanical properties of two-phase Mg-10.73Li-4.49Al-0.52Y alloy processed by ECAP. Chin. J. Nonferrous Metals 2012, 25, 500-508.

28. Tong, L.; Zheng, M.; Chang, H.; Hu, X.; Wu, K.; Xu, S.; Kamado, S.; Kojima, Y. Microstructure and mechanical properties of $\mathrm{Mg}-\mathrm{Zn}-\mathrm{Ca}$ alloy processed by equal channel angular pressing. Mater. Sci. Eng. A 2009, 523, 289-294. [CrossRef]

(C) 2019 by the authors. Licensee MDPI, Basel, Switzerland. This article is an open access article distributed under the terms and conditions of the Creative Commons Attribution (CC BY) license (http://creativecommons.org/licenses/by/4.0/). 